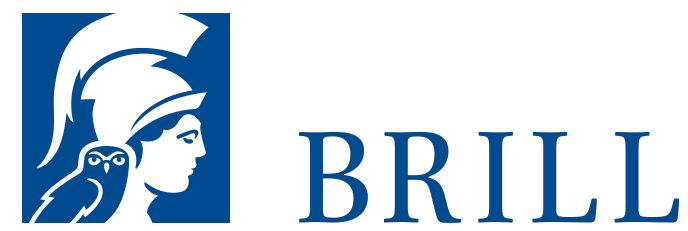

\title{
Die Konzilien auf den Philippinen
}

\author{
Authors: Mariano Delgado and Lucio GutiÃ@rrez
}

Die Philippinen sind das grã $\mid$ ÂŸte katholische Land Asiens. Da sie von 1565 bis 1898 zum spanischen Weltreich geh $\tilde{q}$ rten und von spanischen Ordensleuten evangelisiert wurden, ist ihre Kirchengeschichte der Lateinamerikas vielfach vergleichbar.

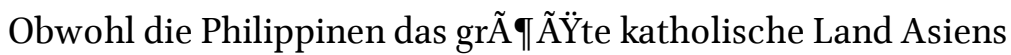
sind, gibt es im deutschen Sprachraum kaum Werke Ã¹/4ber das dortige Christentum. Diese LÃ $1 / 4$ cke soll mit vorliegender Geschichte Ã $1 / 4$ ber 'Die Konzilien auf den Philippinen' geschlossen werden, denn die Konzilien, die es seit der frã $1 / 4$ hen Evangelisierung Ende des 16. Jahrhunderts gegeben hat, sind Brennpunkte, an denen die allgemeine Kirchengeschichte der Philippinen besonders sichtbar wird. Nach einem einfÃ $1 / 4$ hrenden $\hat{a} €^{\prime \prime}$ und fã $1 / 4$ r den deutschen Sprachraum einmaligen â€ $€^{\prime}$ Ãœberblick Ã 1/4ber die Kirchengeschichte auf den Philippinen vom 16. Jahrhundert bis zur Gegenwart, befassen sich die einzelnen Kapitel mit den verschiedenen Konzilien auf den Philippinen, die fã $1 / 4 \mathrm{r}$ das ganze Land von Bedeutung waren: die Junta oder Synode von Manila (1582â€"1583), das 'I.' Konzil von Manila (1771), das im Schatten des Regalismus stattfand und kirchenrechtlich nicht anerkannt wurde, das I. Konzil von Manila (1907), das I. Plenarkonzil der Philippinen (1953) und das II. Plenarkonzil der Philippinen (1991). Ausfã $1 / 4$ hrliche Literatur und verschiedene Register schlieÃŸen den Band ab.

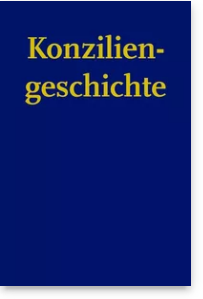

Pages: 304

Seiten

Language:

German

Subjects:

General,

Theology and

World

Christianity

Publisher: Brill |

SchÃ ๆningh

Series:

Konziliengeschichte

- Reihe A:

Darstellungen

E-Book (PDF)

Released online:

15 Jul 2019

ISBN: 978-3-

657-74677-4

List price

USD A A $\$ 111.00$

Hardback

Publication date:

12 Dec 2007

ISBN: 978-3-

5०6-74677-1

List price

USD Â \$111.00 
For more information see brill.com

Order information: Order online at brill.com +44330 333 0049 | customerservices@brill.com Submission information: brill.com/authors

Titles published by Brill | Fink, Brill | mentis or Brill | Schöningh: +49(o)715413279216| brill@brocom.de 